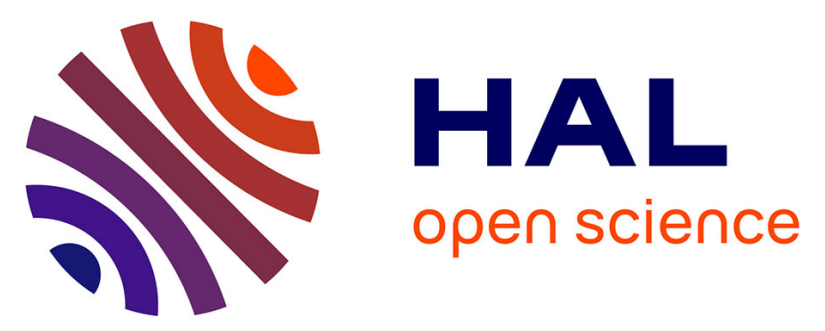

\title{
Inhibitory effect of black tea, lemon juice, and other beverages on salivary and pancreatic amylases: What impact on bread starch digestion? A dynamic in vitro study
}

Daniela Freitas, Steven Le Feunteun

\section{To cite this version:}

Daniela Freitas, Steven Le Feunteun. Inhibitory effect of black tea, lemon juice, and other beverages on salivary and pancreatic amylases: What impact on bread starch digestion? A dynamic in vitro study. Food Chemistry, 2019, 297, pp.124885. 10.1016/j.foodchem.2019.05.159 . hal-02265921

\section{HAL Id: hal-02265921 \\ https://hal.science/hal-02265921}

Submitted on 12 Aug 2019

HAL is a multi-disciplinary open access archive for the deposit and dissemination of scientific research documents, whether they are published or not. The documents may come from teaching and research institutions in France or abroad, or from public or private research centers.
L'archive ouverte pluridisciplinaire HAL, est destinée au dépôt et à la diffusion de documents scientifiques de niveau recherche, publiés ou non, émanant des établissements d'enseignement et de recherche français ou étrangers, des laboratoires publics ou privés. 


\title{
Inhibitory effect of black tea, lemon juice, and other beverages on salivary and pancreatic amylases: What impact on bread starch digestion? A dynamic in vitro study
}

\author{
Daniela Freitas, Steven Le Feunteun* \\ UMR GMPA, AgroParisTech, INRA, Université Paris-Saclay, 78850 Thiverval-Grignon, France
}

\section{A R T I C L E I N F O}

\section{Keywords:}

Saliva

Bread

Lemon juice

Tea

Vinegar

Glycemic response

\begin{abstract}
A B S T R A C T
Certain food properties (ex.: pH, polyphenolic composition) can inhibit digestive amylases and thereby slow down starch digestion. Our aim was twofold. (1) To determine the impact of 21 beverages and condiments (coffees, teas, wines, vinegars and lemon juice) on salivary and pancreatic amylolysis: inhibition ranged from $10 \%$ to $100 \%$ in our experimental conditions. (2) To investigate the effect of one black tea and lemon juice (selected for their strong inhibitory capacity) on starch hydrolysis during dynamic oro-gastro-intestinal digestion of bread. Compared to water (control), the effect of black tea was limited to $a \approx 20 \%$ reduction of released oligosaccharides during the intestinal phase. Lemon juice had a remarkable effect, completely interrupting gastric amylolysis by salivary amylase via a preliminary acidification of gastric contents. These results provide a strong biochemical rationale for the development of dietary strategies to improve the glycaemic impact of starch-rich meals which could be tested in vivo.
\end{abstract}

\section{Introduction}

Hyperglycemia has been associated with a high risk of developing metabolic diseases such as obesity, type-2 diabetes mellitus and cardiovascular disease (Blaak et al., 2012). Tight glycemic control is therefore necessary to maintain health and prevent disease (Blaak et al., 2012). Starch-rich foods constitute a key source of exogenous glucose and therefore play a determining role on postprandial glycemic excursions. The digestion of starch is initiated in the mouth by salivary $\alpha$ amylase (HSA), which starts hydrolyzing starch molecules (Gropper \& Smith, 2013). This enzyme can carry on the amylolytic process in the stomach until it is inactivated by the increasing acidity, between $\mathrm{pH} 3$ and 4 (Freitas, Le Feunteun, Panouille, \& Souchon, 2018; Fried, Abramson, \& Meyer, 1987). Pancreatic $\alpha$-amylase and brush-border enzymes then resume amylolysis in the small intestine, where glucose, the final product of starch digestion, is finally absorbed (Gropper \& Smith, 2013).

The inhibition of digestive amylases can slow down starch digestion, thereby constituting an opportunity to delay the uptake of starch-derived glucose and improve postprandial glycemic responses. Indeed, this strategy has been considered effective in contexts in which glycemic control poses an even bigger challenge than in healthy populations. An example is the treatment of type- 2 diabetes via the administration of acarbose, an inhibitor of amylolytic enzymes in the digestive tract (Salvatore \& Giugliano, 1996). A simple dietary strategy to achieve a lower glycemic response by pairing starch-rich foods, or meals, with food products that can somehow exert a similar inhibitory effect might therefore benefit both healthy individuals and those for whom glycemia management poses a challenge.

We have previously shown that HSA can play a much more important role in starch hydrolysis than generally considered (Freitas \& Le Feunteun, 2019; Freitas et al., 2018). We thereafter provide evidences that pairing starch-rich foods with an acidic food product could slow down starch digestion by premature acid inhibition of HSA (Freitas \& Le Feunteun, 2018), and that this mechanism might contribute to elucidate a number of results from clinical studies in which the glycemic response to starch-rich meals was reduced in the presence of an acidic product (Brighenti et al., 1995; Johnston, Steplewska, Long, Harris, \& Ryals, 2010; Leeman, Östman, \& Björck, 2005; Östman, Granfeldt, Persson, \& Björck, 2005). Additionally, other properties of foods can also inhibit amylases. An example is the reported effect of tea and tea extracts due to their polyphenolic composition. (Hara \& Honda, 1990; Kashket \& Paolino, 1988; Kwon, Apostolidis, \& Shetty, 2008; QuesilleVillalobos, Torrico, \& Ranilla, 2013; Striegel, Kang, Pilkenton, Rychlik, \& Apostolidis, 2015; Zhang \& Kashket, 1998).

The different sites of action of amylolytic enzymes in the digestive

\footnotetext{
* Corresponding author.

E-mail address: steven.le-feunteun@inra.fr (S. Le Feunteun).
} 
tract determine their vulnerability. HSA for example is present during the oral and gastric phases. It is therefore exposed not only to the food components, but also to their $\mathrm{pH}$ and structural characteristics. In turn, pancreatic $\alpha$-amylase, is more likely to be affected by the composition of food only, since the $\mathrm{pH}$ of the chime is rapidly neutralized in the duodenum and the structure of the food has already been largely disrupted at this stage. Logically, the extent of their contribution to the digestive process will also influence the magnitude of the effects that can be achieved by inhibiting each enzyme.

The aims of this work was to screen commonly available beverages and condiments for their capacity to inhibit the amylolytic activity of saliva and pancreatin, and to study the effect of two of them (selected for their observed inhibitory capacity) during dynamic in vitro digestions of a commercial sandwich bread.

\section{Materials and methods}

\subsection{Materials}

Crustless, white, wheat-based sandwich bread (Harry's 100\% Mie Nature, Barilla France S.A.S, Boulogne-Billancourt, France), 2 instant coffees, 3 green teas, 9 black teas, 1 rosé wine, 1 white wine, 1 red wine, 3 vinegars (from white wine, red wine and apple cider), 1 lemon juice and mineral water were bought at a local supermarket. For simplification purposes, all products were coded with randomly allocated letters that do not reflect the brand of the products. All these details can be found in the Supplementary data - Table 1.

Frozen human saliva pooled from 10 donors (Normal saliva in $5 \mathrm{~mL}$ aliquots, ref. 991-05-P-5) was purchased from Lee Biosolutions (Maryland Heights, United States). Porcine pepsin (P-6887) and pancreatin (P1750, 4USP) were from Sigma-Aldrich (Saint-Quentin Fallavier, France). Amyloglucosidase from Aspergillus Niger (ref. 10102857 001) was from Roche (Rotkreuz, Swizerland). The substrate used for the determination of HSA activity was potato starch (ref. 101 253, from Merck, Darmstadt, Germany). D-Glucose kits (ref. 103.21) were acquired from BioSenTec (Auzeville Tolosane, France). All other chemical reagents were of classical analytical grade.

The amyloglucosidase activity provided by the manufacturer (14 U/ $\mathrm{mg}$ ) was used as reference. The activities of saliva $(345 \pm 37 \mathrm{U} / \mathrm{mL})$, pepsin $(3319 \pm 70 \mathrm{U} / \mathrm{mg})$ and pancreatin (Trypsic activity of $3.42 \pm 0.04 \mathrm{U} / \mathrm{mg}$ ), measured according to previously described methods (Minekus et al., 2014), were used as a reference for digestion experiments and analytical assays.

\subsection{Bread composition and preparation of beverages and condiments}

The composition of bread is presented in Table 1. The water, total, digestible and resistant starch contents of the bread used in the digestion experiments were determined as previously described (Freitas et al., 2018). The product label was used as reference for the other components.

Teas and coffees were freshly brewed $(1 \% \mathrm{w} / \mathrm{v})$ with mineral water $\left(100{ }^{\circ} \mathrm{C}\right)$. Teas were infused for $15 \mathrm{~min}$ before the tea bags were

\section{Table 1}

Composition of the white sandwich bread.

\begin{tabular}{ll}
\hline Fat $^{1}(\mathrm{~g} / 100 \mathrm{~g}$ of bread $)$ & 4.3 \\
Water $^{2}(\mathrm{~g} / 100 \mathrm{~g}$ of bread $)$ & $36.1 \pm 0.7$ \\
Total carbohydrates $^{1}(\mathrm{~g} / 100 \mathrm{~g}$ of bread $)$ & 48.5 \\
Total Starch $^{2}(\mathrm{~g} / 100 \mathrm{~g}$ of bread) & $38.7 \pm 4.2$ \\
${\text { Digestible } \text { starch }^{2}(\% \text { of total starch) }}^{\text {Resistant starch }}$ (\% of total starch) & $94.4 \pm 1.5$ \\
Fibre $^{1}(\mathrm{~g} / 100 \mathrm{~g}$ of bread) & $5.6 \pm 1.5$ \\
Protein $^{1}(\mathrm{~g} / 100 \mathrm{~g}$ of bread $)$ & 3.8 \\
\end{tabular}

\footnotetext{
1 According to the label of the product.

2 Experimentally determined as previously described (Freitas et al., 2018).
}

removed. Teas, coffees, all other beverages and the vinegars were used at room temperature.

\subsection{Impact of beverages and condiments on the amylolytic activity of saliva and pancreatin}

The amylolytic activity of saliva, of porcine pancreatin in simulated intestinal fluid electrolyte solution (eSIF) (Minekus et al., 2014), as well as the inhibitory effects of the products listed in Table 1 (Supplementary data) were determined using an adapted version of Bernfeld's method (Bernfeld, 1955), as further described.

\subsubsection{Amylolytic activity of saliva and pancreatin}

A $2 \%(\mathrm{w} / \mathrm{v})$ starch solution was prepared in $0.32 \mathrm{M}$ sodium acetate buffer $(\mathrm{pH}=4.75)$. Four glass tubes were prepared with $0.25 \mathrm{~mL}$ of starch solution and $0.25 \mathrm{~mL}$ of deionised water. Each tube was then incubated $\left(3 \mathrm{~min}, 20^{\circ} \mathrm{C}\right)$ with a different volume $(0,50,70$ or $100 \mu \mathrm{L})$ of either saliva (10-fold diluted ( $\mathrm{w} / \mathrm{w})$ in deionised water), or pancreatin (a $0.75 \mathrm{mg} / \mathrm{mL}$ solution prepared in eSIF). The enzymatic reaction was interrupted by adding $0.5 \mathrm{~mL}$ of DNS solution (consisting of $96 \mathrm{mM} \mathrm{3,5-}$ Dinitrosalicyclic Acid, $0.5 \mathrm{M} \mathrm{NaOH}$ and $0.16 \mathrm{M}$ of potassium tartrate). The volume of enzymatic solution in each tube was then standardized to $100 \mu \mathrm{L}$, and all tubes were placed in a boiling water-bath for $15 \mathrm{~min}$. After cooling to room temperature on ice, $4.95 \mathrm{~mL}$ of water was added. Finally, a spectrophotometric measurement at $540 \mathrm{~nm}$ (UV-Vis spectrometer Evolution 201, Thermo Fisher Scientific, Massachusetts, United States) was performed and the concentration in maltose equivalents was determined from a previously established calibration curve. Enzymatic activity was defined as follows: 1 unit liberated $1.0 \mathrm{mg}$ of maltose equivalent in $3 \mathrm{~min}$ at $\mathrm{pH} 6.9$ at $20^{\circ} \mathrm{C}$.

\subsubsection{Inhibitory effect of beverages and condiments on the amylolytic} activity of saliva and pancreatin

The impact of each beverage or condiment on the amylolytic activities of saliva and pancreatin was investigated by substituting, in the previously described procedure, the $0.25 \mathrm{~mL}$ of deionised water by $0.25 \mathrm{~mL}$ of the product of interest. Coffees and teas $(\mathrm{pH} 6.5 \pm 0.5)$, were used as prepared. Acidic products (wines, vinegars and lemon juice) were studied in both natural and neutralized forms with saliva, but only in the neutralized form with pancreatin. Indeed, the $\mathrm{pH}$ of the chime is quickly neutralized in the duodenum, so that it is unlikely that pancreatic enzymes are affected by the native $\mathrm{pH}$ of foods.

\subsection{Stability of HSA in saliva after exposure to acid environment}

The enzymatic activity of HSA following exposure of saliva to acidic environments was investigated as follows. Seven tubes containing $4 \mathrm{~mL}$ of simulated gastric electrolyte fluid (eSGF) (Minekus et al., 2014) at different $\mathrm{pHs}$ were prepared (using diluted $\mathrm{HCl}$ ), and incubated at $37^{\circ} \mathrm{C} .1 \mathrm{~mL}$ of saliva (10 fold diluted in deionised water) pre-warmed to $37^{\circ} \mathrm{C}$, was then added to each tube, the final $\mathrm{pH}$ of the mixtures ranged from 1.5 to 3.9. Samples $(750 \mu \mathrm{L})$ were collected from each tube at 0.5 , $15,30,60$ and $120 \mathrm{~min} .750 \mu \mathrm{L}$ of $\mathrm{NaOH}$ solutions of pre-calibrated concentrations were immediately added to neutralize the $\mathrm{pH}$ of the samples to $6.9 \pm 0.5$. Samples were conserved at $-20^{\circ} \mathrm{C}$ until analysis using the control assay for determination of the amylolytic activity of saliva.

\subsection{In vitro oro-gastrointestinal digestion}

Bread digestion protocols can be divided into two groups: (1) control digestions, which aimed at studying the respective contributions of the two amylolytic enzymes to starch hydrolysis, and (2) experimental digestions, conducted to assess the impact of tea and lemon juice on starch hydrolysis. With the exception of the control digestion with no saliva nor pancreatin, all digestion experiments were performed in 

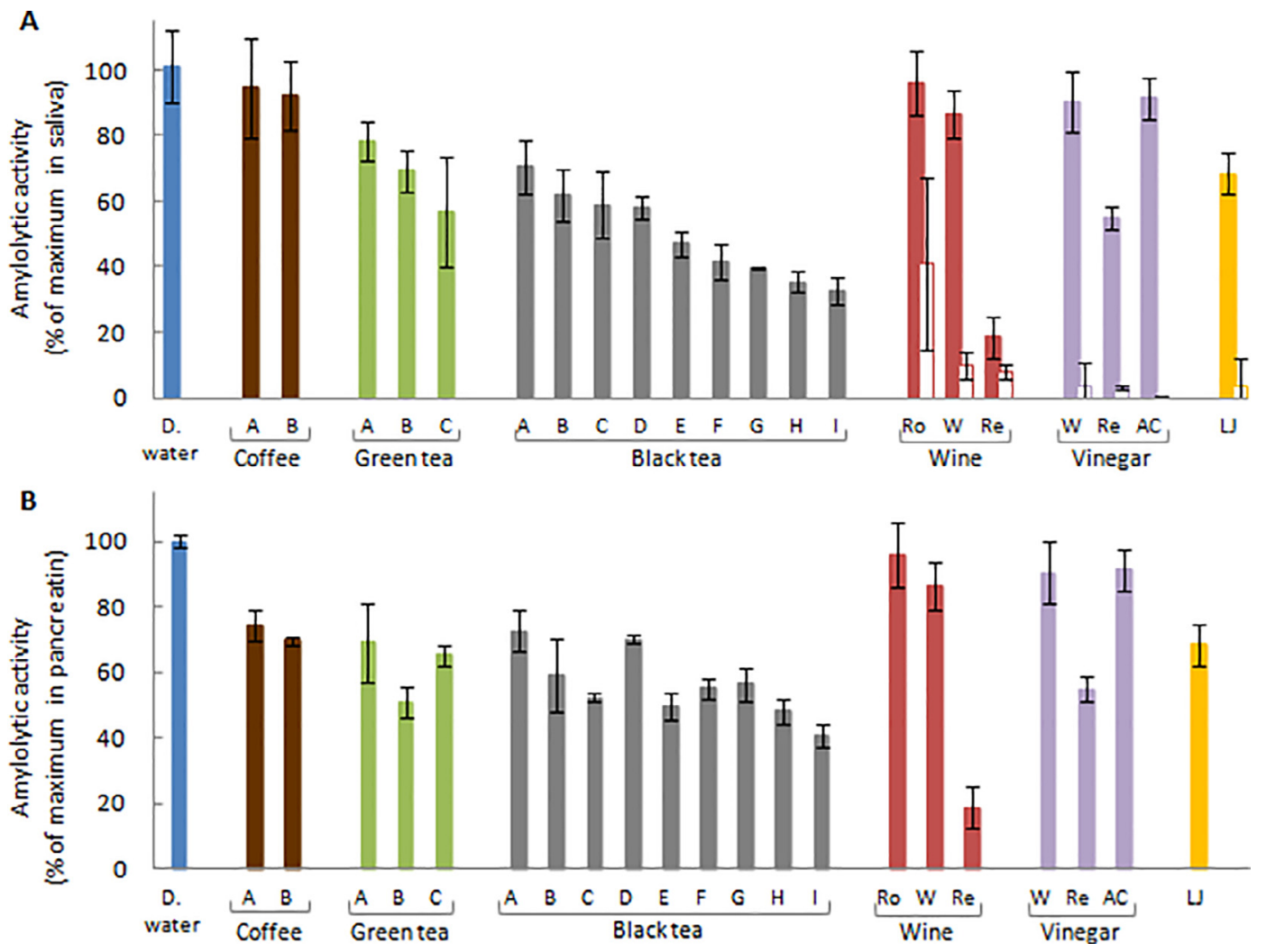

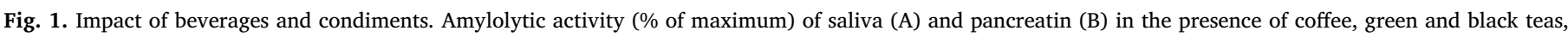

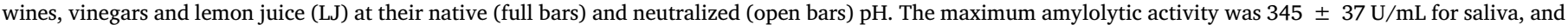
$24 \pm 1 \mathrm{U} / \mathrm{mg}$ for pancreatin. Data represent mean $\pm \mathrm{SD}, 3 \mathrm{rpt}$.

triplicate. They comprised a manual oral phase that immediately preceded gastrointestinal digestions in a dynamic in vitro system, DiDGI ${ }^{\circledast}$ (INRA, Grignon, France), controlled and monitored by the software STORM $^{\circledR}$ (INRA, Grignon, France). The standardized Infogest static in vitro digestion method (Minekus et al., 2014) was used as reference to define the composition, the fluxes and activities of the gastrointestinal secretions. Since our dynamic digestion protocol and the sample analysis procedures have been previously described in detail, only the main experimental steps, key principles and adaptations are presented here. Interested readers are invited to refer to (Freitas \& Le Feunteun, 2019) for further information.

\subsubsection{Oral phase}

After processing bread in a food chopper (Multi-moulinette $400 \mathrm{CW}$, Moulinex, Ecully, France) each bolus was formed by mixing $6 \mathrm{~g}$ portions with $1.2 \mathrm{~mL}$ of saliva (pre-heated to $37^{\circ} \mathrm{C}$ ) for $30 \mathrm{~s}$ with a spatula. The proportion of saliva and mixing time were based on Human studies (Hoebler et al., 1998; Jourdren et al., 2016).

\subsubsection{Gastric phase}

Immediately after preparation, each bolus was introduced in the DiDGI ${ }^{\circledR}$ 's gastric compartment $\left(37^{\circ} \mathrm{C}\right.$, stirring speed of $\left.10 \mathrm{rpm}\right)$, containing $20 \mathrm{~mL}$ of eSGF at neutral $\mathrm{pH}, 10 \mu \mathrm{L}$ of $0.3 \mathrm{M} \mathrm{CaCl}_{2}$, and $12.8 \mathrm{~mL}$ of deionised water. The chime was stirred for $30 \mathrm{~s}$, and interrupted for another $30 \mathrm{~s}$ to collect a first sample $(2 \mathrm{~mL})$ from the supernatant. Stirring was then resumed and the gastric phase was initiated by activating the fluxes of pepsin $(4705 \mathrm{U} / \mathrm{mL}$ in eSGF) and $\mathrm{HCl}(0.1 \mathrm{M}$ in eSGF). The pepsin flux was set to reach $\approx 2000 \mathrm{U}$ per $\mathrm{mL}$ of chime at $\mathrm{t}=90 \mathrm{~min}$, and was stopped afterwards. The flux of $\mathrm{HCl}$ was automatically adjusted to decrease the $\mathrm{pH}$ of the chime by 1 unit every 22.5 min until pH 2.0 was reached, and keep it constant thereafter, in order to replicate the kinetics of gastric acidification observed in humans (Malagelada, Go, \& Summerskill, 1979). The gastric phase lasted $120 \mathrm{~min}$.

\subsubsection{Intestinal phase}

$22 \mathrm{~mL}$ of eSIF, $10 \mathrm{~mL}$ of deionised water, and $80 \mu \mathrm{L}$ of $0.3 \mathrm{M} \mathrm{CaCl}_{2}$ were added. The $\mathrm{pH}$ of the chime was adjusted to 7.0 with $1 \mathrm{M} \mathrm{NaOH}$ and the intestinal phase was initiated by adding $10 \mathrm{~mL}$ of a pancreatin solution in eSIF to double the final volume of the gastric chime and reach a trypsin activity of $100 \mathrm{U} / \mathrm{mL}$. The intestinal compartment of $\operatorname{DiDGI}^{\circledast}\left(37^{\circ} \mathrm{C}, 10 \mathrm{rpm}\right)$ was programmed to automatically maintain the $\mathrm{pH}$ at 7.0 by adding $0.02 \mathrm{M} \mathrm{NaOH}$. The intestinal phase lasted $120 \mathrm{~min}$.

\subsubsection{Sampling}

In addition to the first sample (collected from the gastric compartment $1 \mathrm{~min}$ after the oral phase, and approximately $30 \mathrm{~s}$ before gastric digestion started), additional samples were collected from the chime's supernatant at 5, 15, 30, 60, 120, 125, 135, 150, 180 and $240 \mathrm{~min}$. Each sample $(2 \mathrm{~mL}$ ) was collected after interrupting stirring for $30 \mathrm{~s}$ to allow particles to sediment, and was immediately transferred to a dry bath (ThermoMixer C, Eppendorf, Hamburg, Germany) $\left(99^{\circ} \mathrm{C}, 150 \mathrm{rpm}\right.$, $5 \mathrm{~min}$ ) for enzyme inactivation. Samples were kept at $-20^{\circ} \mathrm{C}$ until required for further analysis.

\subsubsection{Bread starch digestion - control experiments}

Three different experiments were carried out: (1) with no saliva nor pancreatin, (2) with saliva but without pancreatin, (3) without saliva but with pancreatin. To do so, saliva and the pancreatin solution were replaced with deionised water and eSIF, respectively, when needed.

2.5.6. Bread starch digestion in presence of water, black tea and lemon juice

Three different digestions were carried out. In each experiment, $7.4 \mathrm{~mL}$ of deionised water out of the $12.8 \mathrm{~mL}$ added at the start of the 
gastric phase were replaced with the same volume of either (1) mineral water, (2) black tea, or (3) lemon juice $(\mathrm{pH}=2.3)$.

\subsubsection{Analysis of dynamic digestion samples}

All samples were centrifuged (Centrifuge 5804 R, Eppendorf, Hamburg, Germany) (10 min, $3000 \mathrm{~g}$ and $4{ }^{\circ} \mathrm{C}$ ), and the supernatants were analysed to quantify the released starch and oligosaccharides. Released starch was quantified as glucose equivalents (using D-Glucose kits) after complete hydrolysis by amyloglucosidase. Oligosaccharides with degrees of polymerization up to 10 were quantified in the same way after selective polysaccharide precipitation in an $80 \%(\mathrm{v} / \mathrm{v})$ ethanol solution (Hoebler et al., 1998).

\section{Results and discussion}

\subsection{Inhibitory effect of beverages and condiments on the amylolytic activity of saliva and pancreatin}

The amylolytic activity of saliva was $345 \pm 37 \mathrm{U} / \mathrm{mL}$. This is close to the results that we $(352 \mathrm{U} / \mathrm{mL})$ (Freitas et al., 2018) and other researchers (410 U/mL) (Bernfeld, 1955) have previously found using the same enzymatic assay. The amylolytic activity of pancreatin was $24 \pm 1 \mathrm{U} / \mathrm{mg}$. The inhibitory effect of the tested products on the amylolytic activity of saliva is presented in Fig. 1A. Starting with the neutral $\mathrm{pH}$ products, coffees, green teas and black teas reduced HSA's activity by $5-10 \%, 20-45 \%$ and $30-70 \%$, respectively. When tested at their native pHs (open bars), wines, vinegars and lemon juice exhibited a very high inhibitory capacity on HSA, which ranged between $90 \%$ and $100 \%$ of inhibition. With the exception of red wine and red wine vinegar, which still inhibited $\approx 82 \%$ and $45 \%$ of HSA's activity in their neutralized form, acidic foods largely lost their inhibitory capacity upon $\mathrm{pH}$ neutralization (full bars). Experiments with pancreatin were conducted after $\mathrm{pH}$ neutralization only, because the $\mathrm{pH}$ of the chime is rapidly neutralized once it is propelled into the duodenum, and comparable inhibition levels were obtained within each product category (Fig. 1B).

Experiments conducted at the native $\mathrm{pH}$ of acidic foods intended to reflect the influence their acidity might exert during the digestive processes that are most likely to be affected by the $\mathrm{pH}$ of foods, specifically oral and gastric amylolysis by HSA. The almost complete inhibition of HSA with wines, vinegars and lemon juice at their native $\mathrm{pHs}$ was expected as it only confirms the previously reported $\mathrm{pH}$ dependence of the amylolytic activity of saliva. The optimum $\mathrm{pH}$ of HSA in saliva is close to 6 and, as the $\mathrm{pH}$ is lowered, its activity is progressively reduced until it is completely lost below pH 3.5 (Freitas et al., 2018; Fried et al., 1987). With the exception of red wine $(\mathrm{pH}=3.7)$, the $\mathrm{pH}$ of all other investigated acidic solutions was below this inactivation threshold (between 2.3 and 3.2), hence explaining their capacity to almost completely inactivate HSA, even after being mixed with the starch solution at a 1:1 volume ratio. After $\mathrm{pH}$ neutralization, important losses of inhibitory levels were observed for almost all acidic foods, hence demonstrating the predominant effect of acidity over other factors, such as the polyphenol content for example, on HSA activity. It is worth noting that the preservation of the inhibitory capacity of red wine and red wine vinegar at neutral $\mathrm{pH}$ can be related with their polyphenol content. The total phenol content of red wine is markedly higher than that of white and rosé wines, on average by a factor between 2 and 9 (Landrault et al., 2001). Similarly, the total phenol content of red wine vinegar is about 2-4 times greater than that of white wine and cider vinegars (Andlauer, Stumpf, \& Fürst, 2000).

Coffee had very limited influence on the activity of neither of both amylolytic enzymes. To the best of our knowledge, there are no studies about the effect of coffee itself, but there is some evidence in the literature showing that some substances isolated from coffee beans exert an inhibitory effect on pancreatic amylase (Funke \& Melzig, 2005; Narita \& Inouye, 2009). It is possible that the concentration of such substances in the prepared coffees was too low for an inhibitory effect to be produced. The effect of tea and tea extracts on the amylolytic activities of salivary $\alpha$-amylase and pancreatic $\alpha$-amylase has been widely studied by different research teams. Most have found similar results to ours, confirming the capacity of different teas to inhibit salivary (Hara \& Honda, 1990; Kashket \& Paolino, 1988; Zhang \& Kashket, 1998) and pancreatic (Kwon et al., 2008; Quesille-Villalobos et al., 2013; Striegel et al., 2015) $\alpha$-amylases in vitro, and reporting that black teas have a higher capacity to inhibit both of these enzymes (Quesille-Villalobos et al., 2013; Zhang \& Kashket, 1998). The same has been observed with tea extracts and purified tea polyphenols (Forester, Gu, \& Lambert, 2012; Miao, Jiang, Jiang, Zhang, \& Li, 2015; Sun, Gidley, \& Warren, 2018; Sun, Warren, Netzel, \& Gidley, 2016; YilmazerMusa, Griffith, Michels, Schneider, \& Frei, 2012). Considering that all teas were prepared in the same way, the variability observed within the green and black teas categories possibly reflects the impact of differences in the cultivation and processing chains of each product. Numerous factors from the growing environment of the plants to the manufacturing conditions and even packaging materials have been reported to influence the composition of the final product (Astill, Birch, Dacombe, Humphrey, \& Martin, 2001).

This reduction of the catalytic activity can be characterized as a mixed-type inhibition as both competitive inhibition (by binding to the active site) (Sun et al., 2016) and non-competitive inhibition (by binding with the enzyme-substrate complex) have been identified (Hara \& Honda, 1990). It is also interesting to note that some teams have observed that this inhibitory capacity is generally higher for the brushborder enzyme $\alpha$-glucosidase (Kwon et al., 2008; Striegel et al., 2015; Yilmazer-Musa et al., 2012) and that it can also impair intestinal glucose uptake as it also applies to specific transporters in the intestinal epithelial wall (Shimizu, Kobayashi, Suzuki, Satsu, \& Miyamoto, 2000). Recently, however, some contradictory results have been published showing that tea polyphenols and tea extracts can actually enhance amylolytic activity at low concentrations (Tong, Zhu, Guo, Peng, \& Zhou, 2018; Yang \& Kong, 2016). Research on the other tested products is less abundant but the observed inhibitory effects of grape seed extracts on HSA (Yilmazer-Musa et al., 2012) and of wine on pancreatic $\alpha$ amylase (Kwon et al., 2008) are also in agreement with our results.

\subsection{Residual amylolytic activity of saliva after exposure to an acid environment}

During digestion, saliva is exposed to an increasingly acidic environment within the stomach before being emptied into the small intestine. It is therefore uncertain how much of the amylolytic activity of saliva can be restored during the intestinal phase of digestion, and thus contribute to the intestinal hydrolysis of starch. These experiments aimed at evaluating the residual amylolytic activity of saliva at neutral $\mathrm{pH}$, after exposure to in vitro gastric conditions at different acidity levels.

According to the results, presented in Fig. 2, three behaviours can be distinguished according to gastric acidity conditions: $\mathrm{pH}>3.5$, $\mathrm{pH} \approx 3.0$, and $\mathrm{pH}<2.5$. When HSA was exposed to $\mathrm{pH} 3.6$ or 3.9 , the amylolytic activity of saliva was fully recovered after $\mathrm{pH}$ neutralization, regardless of the period of incubation. When the $\mathrm{pH}$ was close to 3 (2.9 or 3.1), the residual amylolytic performance was dependent on exposure time. For short ( $30 \mathrm{~s}$ ) exposures, $90 \%-100 \%$ of activity was recovered after $\mathrm{pH}$ neutralization. For longer exposures, amylolytic activity was progressively and irreversibly lost at a pH-dependent rate. Finally, for $\mathrm{pH}<2.5$, HSA activity was irreversibly lost, regardless of exposure time. The presence of starch has been reported to have a protective effect on HSA, preserving up to $56 \%$ of the activity of purified amylase after $1 \mathrm{~h}$ at pH 3 (Rosenblum, Irwin, \& Alpers, 1988). This was not observed in our experiments, however, our results are in agreement with the findings of Bernfeld, Staub, and Fischer (1948) who conducted similar experiments with purified HSA, exposing it to $\mathrm{pH}$ 


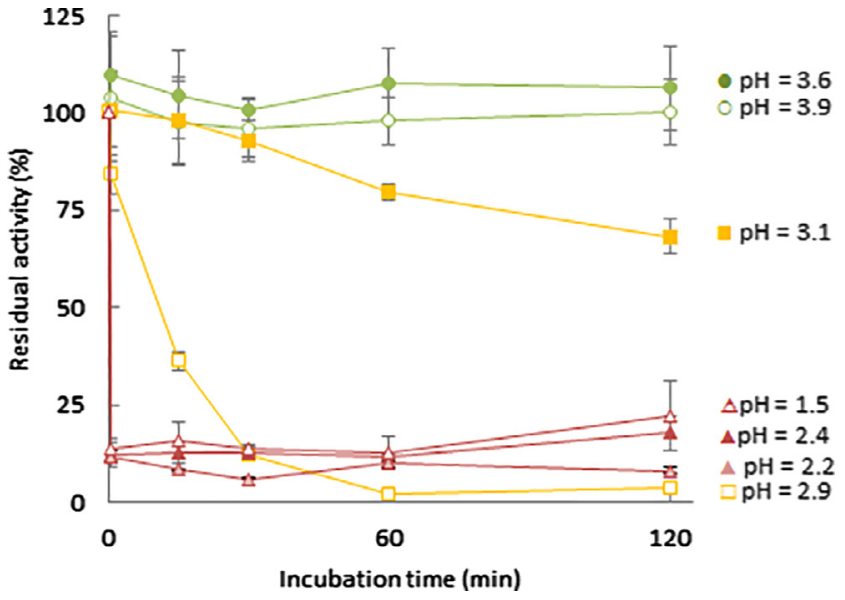

Fig. 2. Impact of exposure of saliva to acidic environments. Residual amylolytic activity of saliva after exposure to $\mathrm{pH}>3.5$ (all circles), $\mathrm{pH} \approx 3.0$ (all squares), and $\mathrm{pH}<2.5$ (all triangles). Each sample was analysed 3 times for remaining HSA activity at $\mathrm{pH}$ 6.9. Data represent mean $\pm \mathrm{SD}, 3 \mathrm{rpt}$.

ranging from 3 to 12 for $30 \mathrm{~min}, 2 \mathrm{~h}$ and $20 \mathrm{~h}$. They observed that between $\mathrm{pH} 4$ and $11,100 \%$ of activity was always recovered. Between $\mathrm{pH} 3$ and 4, the amylolytic activity was still recovered after $30 \mathrm{~min}$ but, as exposure time increased, an increasing proportion of HSA was irreversibly lost. The results of our stability assays, in agreement with the available literature, point towards the existence of a time-dependent irreversible inactivation threshold around $\mathrm{pH}$ 3. However, they also show that despite an impairment of amylolytic activity at acidic $\mathrm{pH}$, whenever HSA is not exposed to $\mathrm{pH} \approx 3$ or below, this effect is reversible. This may be particularly relevant in the context of human carbohydrate digestion. Depending on the properties of the meal, it can take more than $45 \mathrm{~min}$ to lower the $\mathrm{pH}$ of the gastric chime to 4 , and close to $1 \mathrm{~h}$ to further reduce it to 3 (Malagelada et al., 1979). Therefore, HSA in the gastric chime propelled into the small intestine in the first 45-60 min of digestion might fully recover its enzymatic activity and resume amylolysis in combined action with pancreatic $\alpha$-amylase. This is indeed consistent with previous reports that HSA comprised as much as $14 \%$ of the total amylase in the jejunum over a $200 \mathrm{~min}$ period after meal consumption (Fried et al., 1987).

\subsection{Dynamic in vitro digestion of bread starch in presence of water, black tea and lemon juice}

\subsubsection{Bread starch digestion - control digestions}

The results of the control digestions carried out with no saliva nor pancreatin, or either with saliva or pancreatin alone are presented in Fig. 3A-C, respectively. In the absence of amylolytic activity (Fig. 3A), about $15 \%$ of the total starch was solubilised into the surrounding solution within the first minutes of gastric digestion. As the $\mathrm{pH}$ progressively decreased further, the proportion of released starch increased again, reaching a plateau at $25-30 \%$ that lasted until the end of the intestinal phase. This starch release profile can be attributed to a rapid disintegration of bread particles within the gastric medium (Freitas \& Le Feunteun, 2019), and the subsequent hydrolysis of the gluten network by pepsin (Freitas et al., 2018). Indeed, pepsin is inactive in the initial $\mathrm{pH}$ conditions of the gastric phase so that only the effects of mixing and starch diffusion towards the surrounding can explain the initial rise of about $15 \%$. The second increase of about $15 \%$ may, however, be essentially akin to the pepsin action as previously reported (Freitas et al., 2018). Since pepsin is inactive at pH 7 and pancreatin was not used, no further starch was released throughout the intestinal phase. The oligosaccharide fraction, estimated between $4 \%$ and $9 \%$ of the total starch content of bread throughout digestion (Fig. 3A), corresponds to the signal arising from the simple sugars in bread since no amylase was used in this control experiment.

When HSA was the only amylolytic enzyme present (Fig. 3B), considerably more starch and oligosaccharides were released. After $15 \mathrm{~min}$, released starch and oligosaccharides plateaued at about $60-65 \%$ and $37 \%$, respectively. A further increase of $4-5 \%$ seemed to occur within in the first minutes of intestinal digestion. More experiments would be needed to confirm this small apparent increase, which was unexpected according to our results showing an irreversible inactivation of HSA after exposure to the $\mathrm{pH}$ conditions $(\mathrm{pH}=2)$ set for the last stage of gastric digestion. It is therefore possible that part of HSA activity was recovered during the intestinal phase.

In the absence of saliva but in presence of pancreatin (Fig. 3C), the gastric starch and oligosaccharide release profiles were similar to those already described for the experiment free from amylolytic enzymes (Fig. 3A). As soon as the intestinal phase was initiated, the proportion of released starch increased almost instantaneously, plateauing close to $85 \%$ within $15 \mathrm{~min}$, with almost all of it hydrolysed into oligosaccharides. This experiment therefore clearly illustrates the great efficiency of pancreatin to rapidly, and extensively, hydrolyse the starch in the chime emptied from the stomach.

Taking into account the properties of saliva and pancreatin, at the start of the oral, gastric and intestinal phases, amylolytic activity could be estimated at $48 \mathrm{U} / \mathrm{g}, 8 \mathrm{U} / \mathrm{mL}$ and $702 \mathrm{U} / \mathrm{mL}$, respectively. Therefore, considering amylolytic activities per se, intestinal amylolysis could be expected to be predominant over the other stages of digestion. However, despite the lower amylolytic activity in the oral and gastric stages of digestion, the starch hydrolysis patterns were similar to those obtained when only intestinal amylolysis was enabled. This clearly illustrates the importance of physiologic chronology during starch digestion.

3.3.2. Bread starch digestion in presence of water, black tea and lemon juice

The effect of pairing water, lemon juice or tea with bread on starch digestion is shown in Fig. 4A-C, respectively. In the presence of water (Fig. 4A), approximately $15 \%$ of the total starch was released in the form of oligosaccharides after the oral phase. During the gastric phase, amylolysis proceeded and plateaued after about $30 \mathrm{~min}$ at $\sim 70 \%$ of the total starch, more than half of which in the form of oligosaccharides. During the intestinal phase, starch release appeared to have only slightly increased to approximately $80 \%$ of the total starch, and most of the amylolytic activity consisted in hydrolysing the polysaccharides released during the gastric phase into oligosaccharides. This "rise-plateau-rise-plateau" profile was preserved when water was replaced with black tea and lemon juice (Fig. 4B and C) but with different patterns. In presence of tea (Fig. 4B), gastric released starch and oligosaccharide plateaued about $10 \%$ lower. During the intestinal phase, released starch reached the same level as with water, but hydrolysis into oligosaccharides remained impaired, stagnating at about $50 \%$ of the total starch. In presence of lemon juice (Fig. 4C), released starch remained limited to about $40 \%$ of the total bread starch at the gastric stage, and hydrolysis into oligosaccharides was totally interrupted after the oral phase. During the intestinal phase, the proportion of released starch rapidly matched that of the other two experiments. Hydrolysis into oligosaccharides remained close to that obtained in the presence of tea, i.e. slightly lower the level observed with water.

Starch hydrolysis during the digestion of bread with water was highly similar to those we have previously observed with other types of bread (Freitas \& Le Feunteun, 2018, 2019). Our present results therefore provide further confirmation that the gastric phase can importantly contribute to the digestion of starch in bread and other high glycaemic index starchy foods (Freitas \& Le Feunteun, 2018, 2019; Freitas et al., 2018).

In the presence of tea, only about $33 \%$ and $41 \%$ of the amylolytic activity of saliva and pancreatin was preserved with the assays we used to investigate the inhibitory capacity of beverages and condiments (Fig. 1). However, during dynamic in vitro digestions, black tea had a 

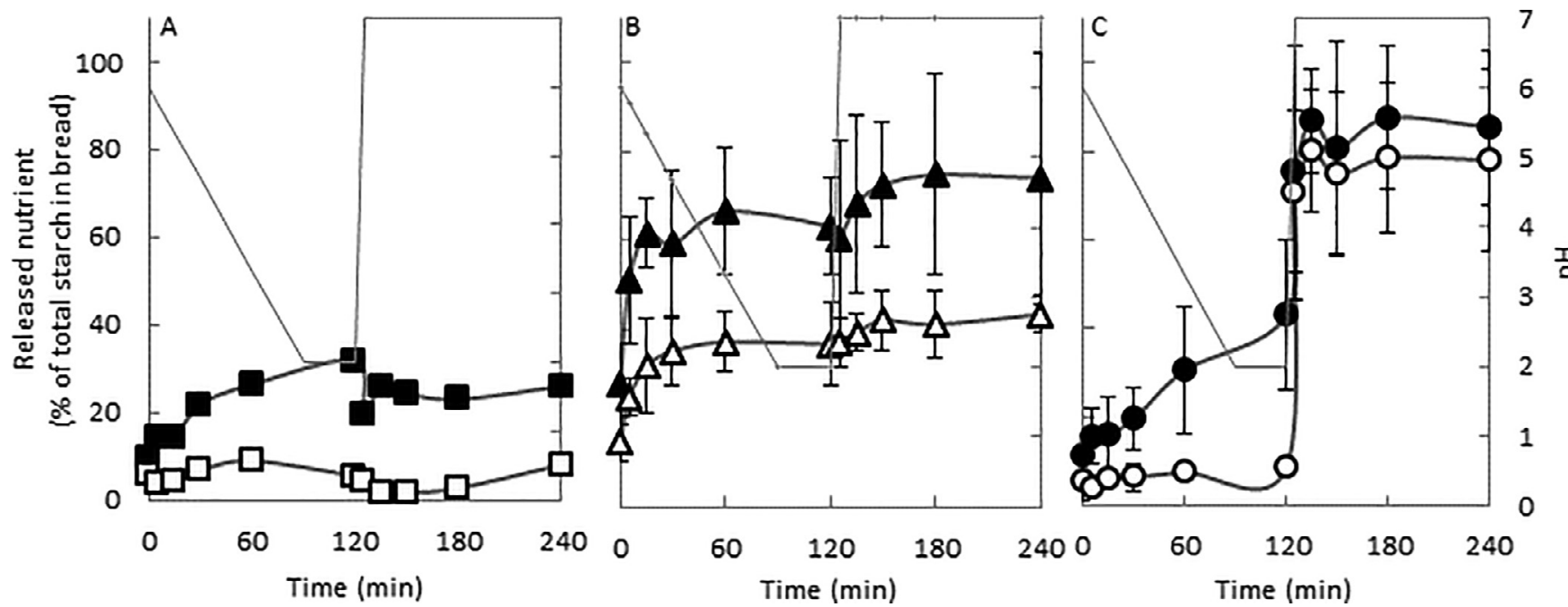

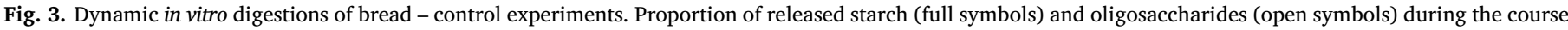

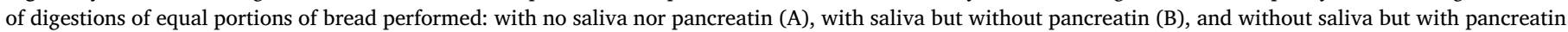
(C). The first point in each curve corresponds to the end of the oral phase and the start of the gastric phase. Data represent mean \pm SD, 3 rpt, for (B) and (C).

negligible influence on the starch and oligosaccharide release kinetics during the gastric phase, and its effect remained limited to a $20 \%$ reduction of oligosaccharides during the intestinal phase (Fig. 4B). The much lower impact of black tea during digestions is most certainly due to the differences between the conditions used for both kinds of experiments (Sections 2.3 and 2.5). In particular, 3 conditions of the in vitro digestion experiments could have contributed to such results: (1) the temperature was higher $\left(37^{\circ} \mathrm{C}\right.$ vs. $20^{\circ} \mathrm{C}$ in the enzymatic assays), (2) the tea was more diluted $(\approx 50 \%$ vol. in the enzymatic assay vs. $32 \%$ vol. at the start of the gastric phase and less than $15 \%$ at the start of the intestinal phase), and (3) the amylolytic activity was greater (saliva was $\approx 1.5$ times more concentrated at the start of the gastric phase, and pancreatin was $>80$ times more concentrated during the intestinal phase). In parallel, starch concentration during the gastric phase was similar to that in the enzymatic assay, and was reduced to about half during the intestinal phase. Both the ratios of amylases to tea and starch to tea were thus higher during the course of the digestion experiments. Because the effect of tea is partly due to competitive inhibition (Sun et al., 2016), it is likely that it was partly reversed by the higher substrate to tea ratio (Blanco \& Blanco, 2017), and since the enzymatic reactions were very rapid, it is likely that even a $\sim 50-60 \%$ reduced initial reaction rate does not result in marked differences. Judging by the lower proportion of starch hydrolysed into oligosaccharides in the intestinal phase, tea might have somewhat limited the later stages of amylolysis, but it is quite unlikely that this could be enough to produce an observable effect in vivo. This finding is consistent with human studies testing the effect of teas combined with meals containing $50 \mathrm{~g}$ of carbohydrates, providing that the masses of tea and starch in the meal digested in vitro would correspond to approximately $125 \mathrm{~mL}$ tea $(1 \% \mathrm{w} / \mathrm{v})$ for one portion of bread containing $50 \mathrm{~g}$ of starch $(\approx 100 \mathrm{~g}$ of bread). Indeed, investigations of the effect of $300 \mathrm{~mL}$ of green tea $(3 \% \mathrm{w} / \mathrm{v})$ with a starch-rich breakfast (Josic, Olsson, Wickeberg, Lindstedt, \& Hlebowicz, 2010), or of including green tea extract $(2 \% \mathrm{w} / \mathrm{w})$ in a starch confection (Sapper et al., 2016) did not reveal any effect on postprandial glucose. It therefore seems that higher concentrations of tea/tea extracts or higher proportions of tea to starch would be needed to achieve a relevant inhibitory effect during digestion.

The replacement of water with lemon juice (Fig. 4C) induced a more noticeable slowdown of starch hydrolysis, in agreement with its previously described capacity to inhibit the amylolytic activity of HSA and pancreatin (Fig. 1). In presence of lemon juice, the digestive pattern of
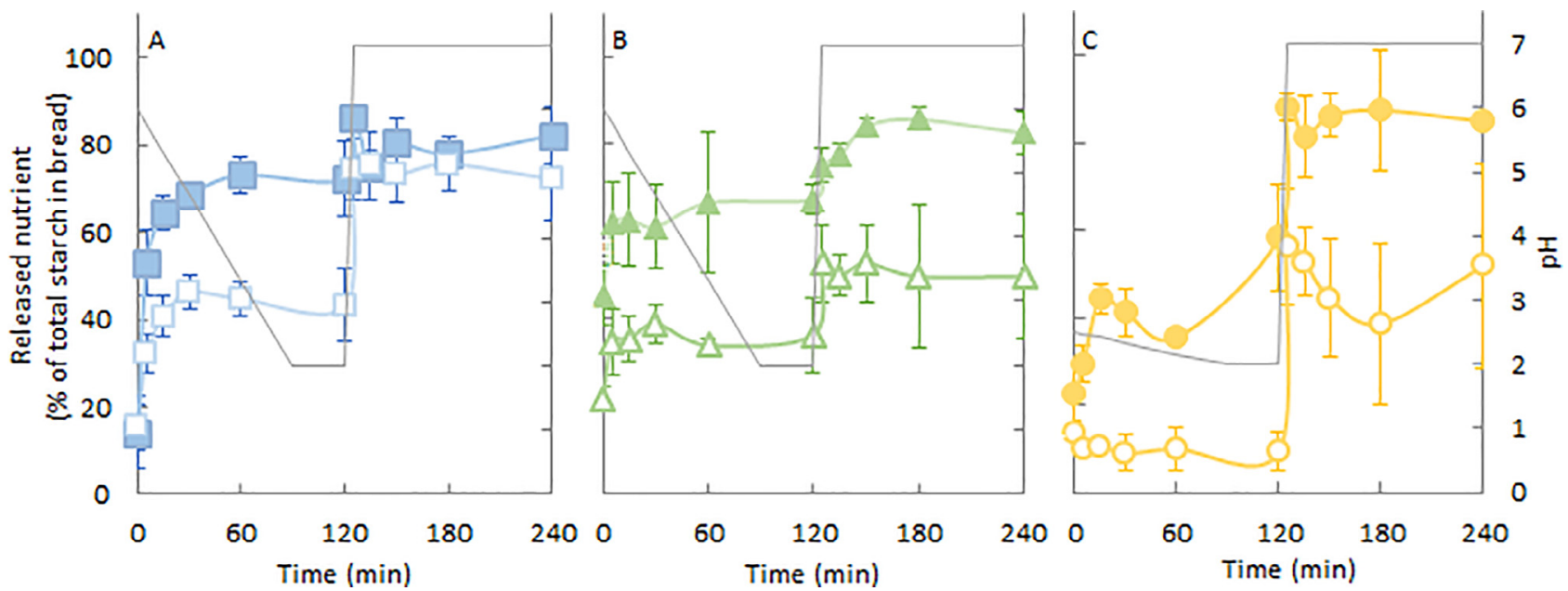

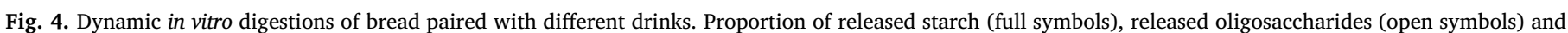

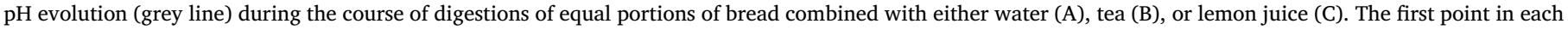
curve corresponds to the end of the oral phase and the start of the gastric phase. Data represent mean \pm SD, $3 \mathrm{rpt}$. 
the control digestion containing only pancreatin (Fig. 3C) was almost reproduced, noting that the earlier increase of released starch during the gastric phase was most certainly due to an earlier $\mathrm{pH}$-activation of pepsin. The magnitude of the effect of lemon juice during the gastric phase therefore directly reflects its inhibitory capacity (Fig. 1A). Indeed, the initial $\mathrm{pH}$ of the chime at the start of the gastric phase was 2.5 in presence of lemon juice, hence inducing a complete inhibition of HSA. These results are in agreement with our previous work showing that pairing 3 starch-rich foods with lemon juice caused an important reduction of gastric amylolysis because of an early acid-induced inhibition of HSA (Freitas \& Le Feunteun, 2018). It is therefore very likely that similar results would have been obtained with the other acidic foods such as vinegars which exhibited an inhibitory capacity equivalent to that of lemon juice (Fig. 1A). In our view, this could explain, at least partly, the effectiveness of the widely studied strategy of supplementing a starch-rich meal with an acidic product (often vinegar) to reduce the glycemic response in vivo (Brighenti et al., 1995; Johnston et al., 2010; Leeman et al., 2005; Östman et al., 2005).

\section{Concluding remarks}

We have shown that green and black teas, red, white and rosé wines, vinegars and lemon juice can all inhibit the amylolytic activity of digestive amylases in enzymatic assays. Under neutral $\mathrm{pH}$ conditions, similar inhibition levels were found for both human saliva and porcine pancreatin. Because saliva is secreted at the very beginning of the digestive system, its amylolytic performance is more susceptible to be impaired by acidic beverages or foods than that of pancreatin. Our results emphasize this aspect as HSA was found to be almost completely inhibited by wines, vinegars and lemon juice when tested at their native pHs. When the capacity of both black tea and lemon juice to slow down bread starch hydrolysis were investigated in more realistic digestion conditions (dynamic in vitro experiments), results were somewhat different. On the one hand, the inhibitory capacity of black tea did not translate into a marked reduction of starch digestion kinetics, probably because of dilution effects and of the very rapid nature of the amylolyis of bread starch with both saliva and pancreatin. On the other hand, the effect of lemon juice observed with the enzymatic assays was confirmed, exerting a much higher effect than tea, with a complete interruption of starch hydrolysis by HSA during the gastric phase of digestion. These in vitro digestion results seem consistent with the available literature on the effects of both tea and acidic foods (generally vinegar) on the glycaemic response to starchy foods. The present study therefore highlights the importance of considering realistic in vitro conditions when evaluating the inhibitory capacity of some products on digestive enzymes. It also provides a biochemical rationale to better understand the effect of acidic foods on the glycaemic response to starch-rich foods, and for the development of related dietary strategies that could be tested in vivo.

\section{Funding}

This research received no external funding.

\section{Acknowledgments}

We would like to thank Thomas Cattenoz and Estelle Canellas for their technical help in the laboratory. We would also like to acknowledge the IDEX-Paris Saclay consortium for partially supporting this research through a $\mathrm{PhD}$ grant and we are grateful to François Boué and Evelyne Lutton for their help in obtaining this doctoral grant.

\section{Declaration of Competing of Interest}

The authors declare no conflict of interest.

\section{Appendix A. Supplementary data}

Supplementary data to this article can be found online at https:// doi.org/10.1016/j.foodchem.2019.05.159.

\section{References}

Andlauer, W., Stumpf, C., \& Fürst, P. (2000). Influence of the acetification process on phenolic compounds. Journal of Agricultural and Food Chemistry, 48(8), 3533-3536.

Astill, C., Birch, M. R., Dacombe, C., Humphrey, P. G., \& Martin, P. T. (2001). Factors affecting the caffeine and polyphenol contents of black and green tea infusions. Journal of Agriculture and Food Chemistry, 49(11), 5340-5347.

Bernfeld, P. (1955). Amylases, $\alpha$ and B. Methods in Enzymology, 1, 149-158.

Bernfeld, P., Staub, A., \& Fischer, E. H. (1948). Sur les enzymes amylolytiques XI. Propriétés de l'a-amylase de salive humaine cristallisée. Helvetica chimica acta, 31(7), 2165-2172.

Blaak, E., Antoine, J. M., Benton, D., Björck, I., Bozzetto, L., Brouns, F., \& Holst, J. (2012) Impact of postprandial glycaemia on health and prevention of disease. Obesity reviews, 13(10), 923-984.

Blanco, A., \& Blanco, G. (2017). Chapter 8 - Enzymes. In A. Blanco, \& G. Blanco (Eds.). Medical biochemistry (pp. 153-175). Academic Press.

Brighenti, F., Castellani, G., Benini, L., Casiraghi, M., Leopardi, E., Crovetti, R., \& Testolin, G. (1995). Effect of neutralized and native vinegar on blood glucose and acetate responses to a mixed meal in healthy subjects. European Journal of Clinical Nutrition, 49(4), 242-247.

Forester, S. C., Gu, Y., \& Lambert, J. D. (2012). Inhibition of starch digestion by the green tea polyphenol,(-)-epigallocatechin-3-gallate. Molecular Nutrition \& Food Research, 56(11), 1647-1654.

Freitas, D., \& Le Feunteun, S. (2018). Acid induced reduction of the glycaemic response to starch-rich foods: The salivary $\alpha$-amylase inhibition hypothesis. Food \& Function, 9(10), 5096-5102.

Freitas, D., \& Le Feunteun, S. (2019). Oro-gastro-intestinal digestion of starch in white bread, wheat-based and gluten-free pasta: Unveiling the contribution of human salivary a-amylase. Food Chemistry, 274, 566-573.

Freitas, D., Le Feunteun, S., Panouille, M., \& Souchon, I. (2018). The important role of salivary alpha-amylase in the gastric digestion of wheat bread starch. Food \& Function, 9(1), 200-208.

Fried, M., Abramson, S., \& Meyer, J. (1987). Passage of salivary amylase through the stomach in humans. Digestive Diseases and Sciences, 32(10), 1097-1103.

Funke, I., \& Melzig, M. (2005). Effect of different phenolic compounds on alpha-amylase activity: Screening by microplate-reader based kinetic assay. Die Pharmazie, 60(10), 796-797.

Gropper, S. S., \& Smith, J. L. (2013). Digestion of polysaccharides. Advanced nutrition and human metabolism (pp. 70.). (6th ed.,). United States of America: Cengage Learning.

Hara, Y., \& Honda, M. (1990). The inhibition of $\alpha$-amylase by tea polyphenols. Agricultural and Biological Chemistry, 54(8), 1939-1945.

Hoebler, C., Karinthi, A., Devaux, M.-F., Guillon, F., Gallant, D. J. G., Bouchet, B., ... Barry, J.-L. (1998). Physical and chemical transformations of cereal food during oral digestion in human subjects. British Journal of Nutrition, 80(5), 429-436.

Johnston, C. S., Steplewska, I., Long, C. A., Harris, L. N., \& Ryals, R. H. (2010). Examination of the antiglycemic properties of vinegar in healthy adults. Annals of Nutrition \& Metabolism, 56(1), 74-79.

Josic, J., Olsson, A. T., Wickeberg, J., Lindstedt, S., \& Hlebowicz, J. (2010). Does green tea affect postprandial glucose, insulin and satiety in healthy subjects: A randomized controlled trial. Nutrition Journal, 9(1), 63.

Jourdren, S., Panouillé, M., Saint-Eve, A., Déléris, I., Forest, D., Lejeune, P., \& Souchon, I (2016). Breakdown pathways during oral processing of different breads: Impact of crumb and crust structures. Food \& Function, 7(3), 1446-1457.

Kashket, S., \& Paolino, V. (1988). Inhibition of salivary amylase by water-soluble extracts of tea. Archives of Oral Biology, 33(11), 845-846.

Kwon, Y.-I., Apostolidis, E., \& Shetty, K. (2008). Inhibitory potential of wine and tea against $\alpha$-amylase and $\alpha$-glucosidase for management of hyperglycemia linked to type 2 diabetes. Journal of Food Biochemistry, 32(1), 15-31.

Landrault, N., Poucheret, P., Ravel, P., Gasc, F., Cros, G., \& Teissedre, P.-L. (2001). Antioxidant capacities and phenolics levels of French wines from different varieties and vintages. Journal of Agriculture and Food Chemistry, 49(7), 3341-3348.

Leeman, M., Östman, E., \& Björck, I. (2005). Vinegar dressing and cold storage of potatoes lowers postprandial glycaemic and insulinaemic responses in healthy subjects. European Journal of Clinical Nutrition, 59(11), 1266.

Malagelada, J.-R., Go, V. L. W., \& Summerskill, W. H. J. (1979). Different gastric, pancreatic, and biliary responses to solid-liquid or homogenized meals. Digestive Diseases and Sciences, 24(2), 101-110.

Miao, M., Jiang, B., Jiang, H., Zhang, T., \& Li, X. (2015). Interaction mechanism between green tea extract and human $\alpha$-amylase for reducing starch digestion. Food Chemistry, 186, 20-25.

Minekus, M., Alminger, M., Alvito, P., Ballance, S., Bohn, T., Bourlieu, C., ... Dufour, C (2014). A standardised static in vitro digestion method suitable for food - An international consensus. Food \& Function, 5(6), 1113-1124.

Narita, Y., \& Inouye, K. (2009). Kinetic analysis and mechanism on the inhibition of chlorogenic acid and its components against porcine pancreas $\alpha$-amylase isozymes I and II. Journal of Agriculture and Food Chemistry, 57(19), 9218-9225.

Östman, E., Granfeldt, Y., Persson, L., \& Björck, I. (2005). Vinegar supplementation lowers glucose and insulin responses and increases satiety after a bread meal in healthy subjects. European Journal of Clinical Nutrition, 59(9), 983. 
Quesille-Villalobos, A. M., Torrico, J. S., \& Ranilla, L. G. (2013). Phenolic compounds, antioxidant capacity, and in vitro $\alpha$-amylase inhibitory potential of tea infusions (Camellia sinensis) commercialized in Chile. CyTA-Journal of Food, 11(1), 60-67.

Rosenblum, J. L., Irwin, C. L., \& Alpers, D. H. (1988). Starch and glucose oligosaccharides protect salivary-type amylase activity at acid pH. American Journal of PhysiologyGastrointestinal and Liver Physiology, 254(5), G775-G780.

Salvatore, T., \& Giugliano, D. (1996). Pharmacokinetic-pharmacodynamic relationships of Acarbose. Clinical Pharmacokinetics, 30(2), 94-106.

Sapper, T. N., Mah, E., Ahn-Jarvis, J., McDonald, J. D., Chitchumroonchokchai, C., Reverri, E. J., ... Bruno, R. S. (2016). A green tea-containing starch confection increases plasma catechins without protecting against postprandial impairments in vascular function in normoglycemic adults. Food \& Function, 7(9), 3843-3853.

Shimizu, M., Kobayashi, Y., Suzuki, M., Satsu, H., \& Miyamoto, Y. (2000). Regulation of intestinal glucose transport by tea catechins. BioFactors, 13(1-4), 61-65.

Striegel, L., Kang, B., Pilkenton, S. J., Rychlik, M., \& Apostolidis, E. (2015). Effect of black tea and black tea pomace polyphenols on $\alpha$-glucosidase and $\alpha$-amylase inhibition, relevant to type 2 diabetes prevention. Frontiers in Nutrition, 2, 3.
Sun, L., Gidley, M. J., \& Warren, F. J. (2018). Tea polyphenols enhance binding of porcine pancreatic $\alpha$-amylase with starch granules but reduce catalytic activity. Food Chemistry, 258, 164-173.

Sun, L., Warren, F. J., Netzel, G., \& Gidley, M. J. (2016). 3 or 3'-Galloyl substitution plays an important role in association of catechins and theaflavins with porcine pancreatic $\alpha$-amylase: The kinetics of inhibition of $\alpha$-amylase by tea polyphenols. Journal of Functional Foods, 26, 144-156.

Tong, D.-P., Zhu, K.-X., Guo, X.-N., Peng, W., \& Zhou, H.-M. (2018). The enhanced inhibition of water extract of black tea under baking treatment on $\alpha$-amylase and $\alpha$ glucosidase. International Journal of Biological Macromolecules, 107, 129-136.

Yang, X., \& Kong, F. (2016). Effects of tea polyphenols and different teas on pancreatic $\alpha$ amylase activity in vitro. LWT-Food Science and Technology, 66, 232-238.

Yilmazer-Musa, M., Griffith, A. M., Michels, A. J., Schneider, E., \& Frei, B. (2012). Inhibition of $\alpha$-amylase and $\alpha$-glucosidase activity by tea and grape seed extracts and their constituent catechins. Journal of Agriculture and Food Chemistry, 60(36), 8924.

Zhang, J., \& Kashket, S. (1998). Inhibition of salivary amylase by black and green teas and their effects on the intraoral hydrolysis of starch. Caries Research, 32(3), 233-238. 